\title{
Epigenetic analyses of the insulin-like growth factor binding protein 1 gene in type 1 diabetes and diabetic nephropathy
}

Tianwei $\mathrm{Gu}^{1 *}$, Henrik Falhammar ${ }^{1,2}$, Harvest F Gu${ }^{1,2}$ and Kerstin Brismar ${ }^{1,2}$

\begin{abstract}
Background: Clinical observations have demonstrated that high levels of circulating insulin-like growth factor binding protein-1 (IGFBP-1) are associated with type 1 diabetes (T1D), whereas low serum IGFBP-1 levels are associated with the risk of type 2 diabetes (T2D). Recently, we reported that increased DNA methylation levels in the IGFBPI gene were associated with T2D. In the present study, we evaluated the epigenetic changes of IGFBPI in T1D and diabetic nephropathy (DN).

Results: In total, 778 Swedish individuals, including T1D patients with or without DN and subjects with the normal glucose tolerance (NGT), were involved in the study. IGFBP1 methylation levels in genomic DNA extracted from peripheral blood were analyzed with bisulfite pyrosequencing. Serum IGFBP-1 levels were measured with radioimmunoassay. We found that DNA methylation levels in the IGFBP1 gene were decreased (15.6\% versus $16.9 \%$; $P<0.001$ ), whereas serum IGFBP-1 levels were increased (31 versus $24 \mu \mathrm{g} / \mathrm{L}, P=0.003$ ) in T1D patients compared with NGT subjects. Furthermore, T1D patients with DN had increased circulating IGFBP-1 concentration compared with the patients without DN (52 versus $28 \mu \mathrm{g} / \mathrm{L} ; P=0.006$ ). However, no difference of the IGFBP1 DNA methylation levels between T1D patients with and without DN was observed.
\end{abstract}

Conclusions: This study shows for the first time that T1D patients had decreased DNA methylation levels in the IGFBP1 gene and further implies that increased circulating IGFBP-1 levels are associated with T1D and DN.

Keywords: IGFBP1, DNA methylation, Type 1 diabetes, Diabetic nephropathy

\section{Background}

Type 1 diabetes (T1D) is an autoimmune disorder characterized by the absence of insulin production, and the patients with T1D require insulin therapy to sustain life. T1D is the most common type of diabetes among children and young adults, but its onset can occur at any age [1]. T1D patients usually develop complications gradually over the years. Diabetic nephropathy (DN) is one of the most common microvascular complications of diabetes, affecting approximately $40 \%$ of individuals with type 1 diabetes [2]. The patients with DN usually start with microalbuminuria and then develop persistent proteinuria, hypertension and declined kidney function. T1D and related DN are complex diseases that result from the combination of

\footnotetext{
* Correspondence: tianwei.gu@ki.se

${ }^{1}$ Rolf Luft Research Center for Diabetes and Endocrinology, Department of Molecular Medicine and Surgery, Karolinska Institutet, Stockholm, Sweden Full list of author information is available at the end of the article
}

genetic and nongenetic factors. In recent years, epigenetic modifications were considered to be involved in the pathogenesis of diabetes and diabetic complications [3-5]. DNA methylation changes are involved in epigenetic regulation mechanisms, which allow alteration of gene function without mutating the sequence. DNA methylation analyses can be performed in the scales of global genome or specific gene regions and in the material of peripheral blood with mixed cell types, particular cell types, or in target tissues [6-8]. Dick et al. [9] recently used both approaches of whole-blood DNA methylation profiling and adipose tissue-specific methylation analysis for study of epigenetic changes related to body mass index (BMI) and suggested that the analysis of blood DNA methylation is worthwhile and can reflect changes in relevant tissues for a phenotype [9].

Circulating insulin-like growth factor binding protein-1 (IGFBP-1) is produced in the liver and is regulated mainly 
by insulin. This protein binds to insulin-like growth factors (IGF-I and IGF-II), acts as a shuttle of IGFs to target tissues, and regulates the activity of free IGF-I [10]. IGFBP-1 is considered to be the principal acute regulator of IGF-I bioactivity and plays an important role in the development of diabetes and complications [11]. Clinical investigations have demonstrated that low circulating levels of IGFBP-1 are associated with type 2 diabetes (T2D) [12-14], whereas high serum IGFBP-1 levels are associated with T1D $[15,16]$. Furthermore, serum IGFBP-1 levels are found to be increased in T1D patients with microalbuminuria [17]. According to our previous study in Swedish middle-aged and elderly twins, heredity estimates were only $36 \%$ for serum IGFBP- 1 levels, which implied that nongenetic factors may contribute to the varied IGFBP-1 levels in diabetes [18]. IGFBP1 gene is located on chromosome $7 \mathrm{p} 12.3$, and a $\mathrm{CpG}$ island resides at the promoter and 5 '-UTR region in this gene. We recently reported that increased DNA methylation levels are associated with T2D in a Swedish population [19]. In this study, we further analyzed DNA methylation changes of IGFBP1 in Swedish T1D patients with and without DN and aimed to evaluate the epigenetic changes of this gene in T1D and DN.

\section{Results}

\section{IGFBP1 DNA methylation changes and serum protein} variation between NGT and T1D

We analyzed DNA methylation levels at six CpG sites (referred to as P1 to P6) of the IGFBP1 gene and found that the IGFBP1 DNA methylation levels at five of the six CpG sites were significantly decreased in T1D patients (P1, 16.8\%; P2, 14.4\%; P3, 11.1\%; P4, 11.9\%; P6, 19.4\%), compared with those in NGT subjects (P1, 17.7\%; P2, 15.6\%; P3, 12.7\%; P4, 13.8\%; P6, 22.2\%; $P=0.004$ for $\mathrm{P} 1, \mathrm{P}<0.001$ for P2, P3, P4, P6), except at P5 (19.7\% in
T1D versus $19.5 \%$ in NGT; $P=0.186$ ). Combining all six CpG sites, the mean levels of IGFBP1 DNA methylation in T1D patients were significantly lower than those in NGT subjects (15.6\% versus $16.9 \% ; P<0.001$, Figure $1 \mathrm{~A})$. On the contrary, IGFBP-1 serum levels in T1D patients were increased compared with those in subjects with NGT $(31 \mu \mathrm{g} / \mathrm{L}$ versus $24 \mu \mathrm{g} / \mathrm{L} ; P=0.005$, Figure $1 \mathrm{~B})$.

We also analyzed the relation of IGFBP1 DNA methylation levels with ages and circulating IGFBP-1 levels. A positive correlation was found between IGFBP1 DNA methylation levels and ages in T1D patients $(r=0.449$; $P<0.001$ ) (Figure 2). Similarly, a correlation was seen between IGFBP1 DNA methylation levels and duration of diabetes in T1D patients $(r=0.240 ; P<0.001)$ and T1D patients with or without DN $(r=0.580$ and 0.425 ; $P<0.001$ for both). Based on this observation, the comparison analyses of IGFBP1 DNA methylation levels and $P$ values, as described earlier, were adjusted by ages. However, no correlation was found between IGFBP1 DNA methylation and circulating IGFBP-1 levels in T1D patients with or without DN.

\section{IGFBP1 DNA methylation changes and serum protein variation between T1D with and without DN}

We further analyzed IGFBP1 DNA methylation changes and serum protein levels in T1D patients with and without DN. No difference appeared in IGFBP1 DNA methylation levels between T1D with and without DN in either males $(16.4 \%$ versus $15.4 \%, P=0.186$; Figure $3 \mathrm{~A})$ or female patients $(15.9 \%$ versus $15.6 \%$; $P=0.604$; Figure $3 B$ ). Compared with T1D patients without DN, however, the IGFBP-1 serum levels in T1D patients with DN were significantly increased in both male $(52 \mu \mathrm{g} / \mathrm{L}$ versus $28 \mu \mathrm{g} / \mathrm{l}$, $P=0.021$, Figure $3 \mathrm{C})$ and female patients $(71 \mu \mathrm{g} / \mathrm{L}$ versus $33 \mu \mathrm{g} / \mathrm{L} ; P=0.003$; Figure 3D). Furthermore, no difference of serum IGFBP-1 levels was found between male and
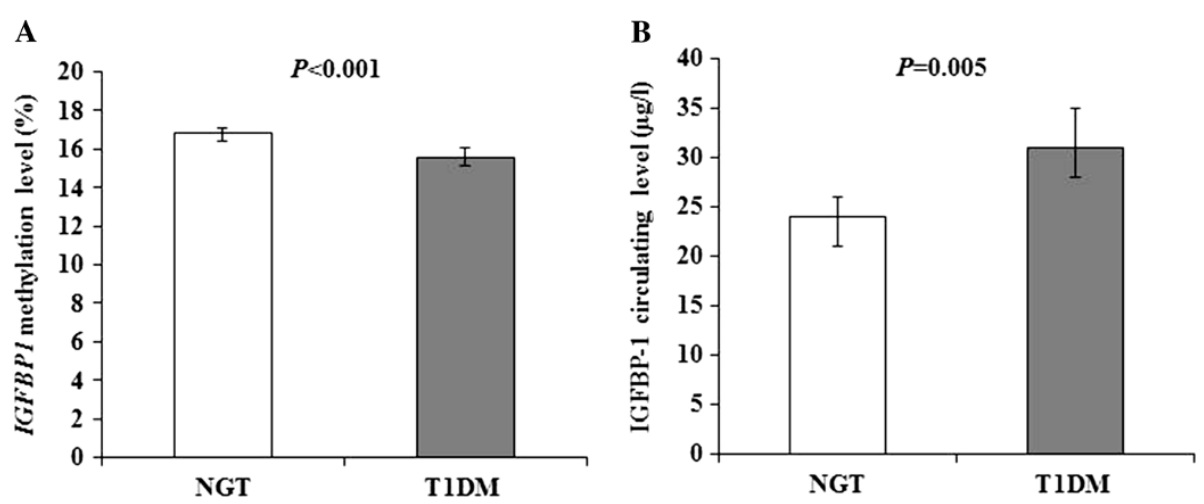

Figure 1 IGFBP1 DNA methylation changes and serum protein variation in Swedish men with normal glucose tolerance and type 1 diabetes. (A) The mean levels of IGFBP1 DNA methylation in T1D patients were significantly lower than those in NGT subjects (15.6\% versus 16.9\%; $P<0.001$, adjusted for age). (B) IGFBP-1 serum levels in T1D patients were increased compared with subjects with NGT (31 $\mu \mathrm{g} / \mathrm{L}$ versus $24 \mu \mathrm{g} / \mathrm{L} ; P=0.005)$. 


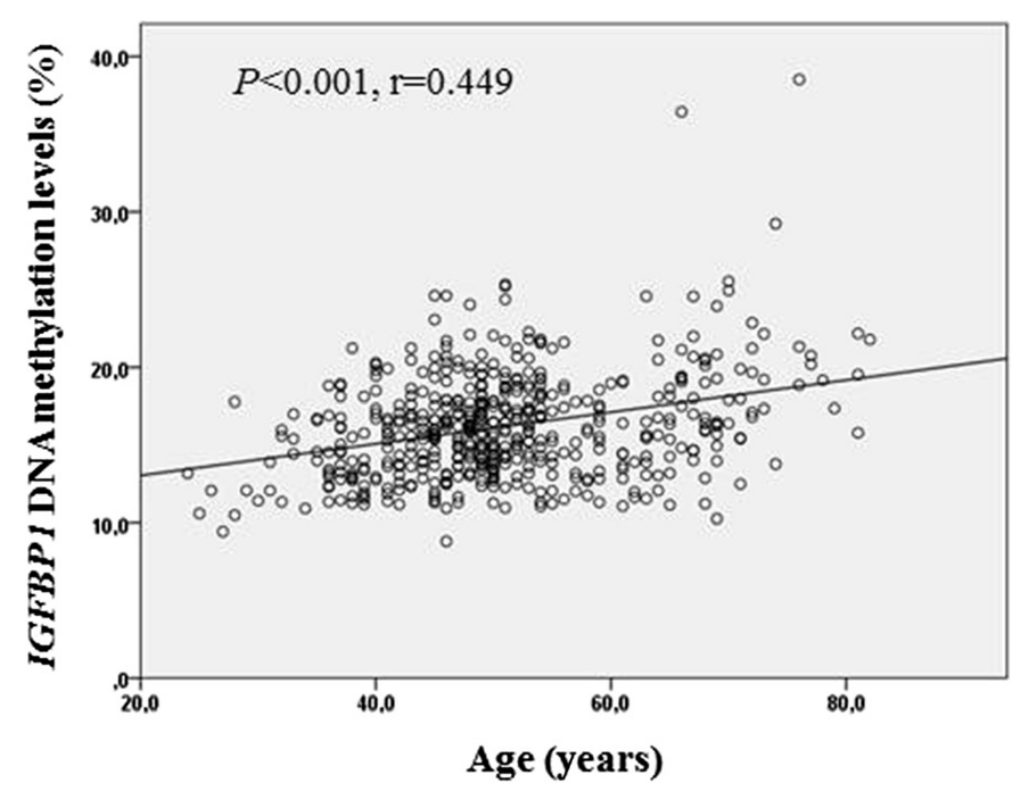

Figure 2 Correlation of IGFBP1 DNA methylation levels with ages in Swedish type 1 diabetes patients. A positive correlation appeared between IGFBP1 DNA methylation levels and ages in T1D patients $(r=0.449 ; P<0.001)$.
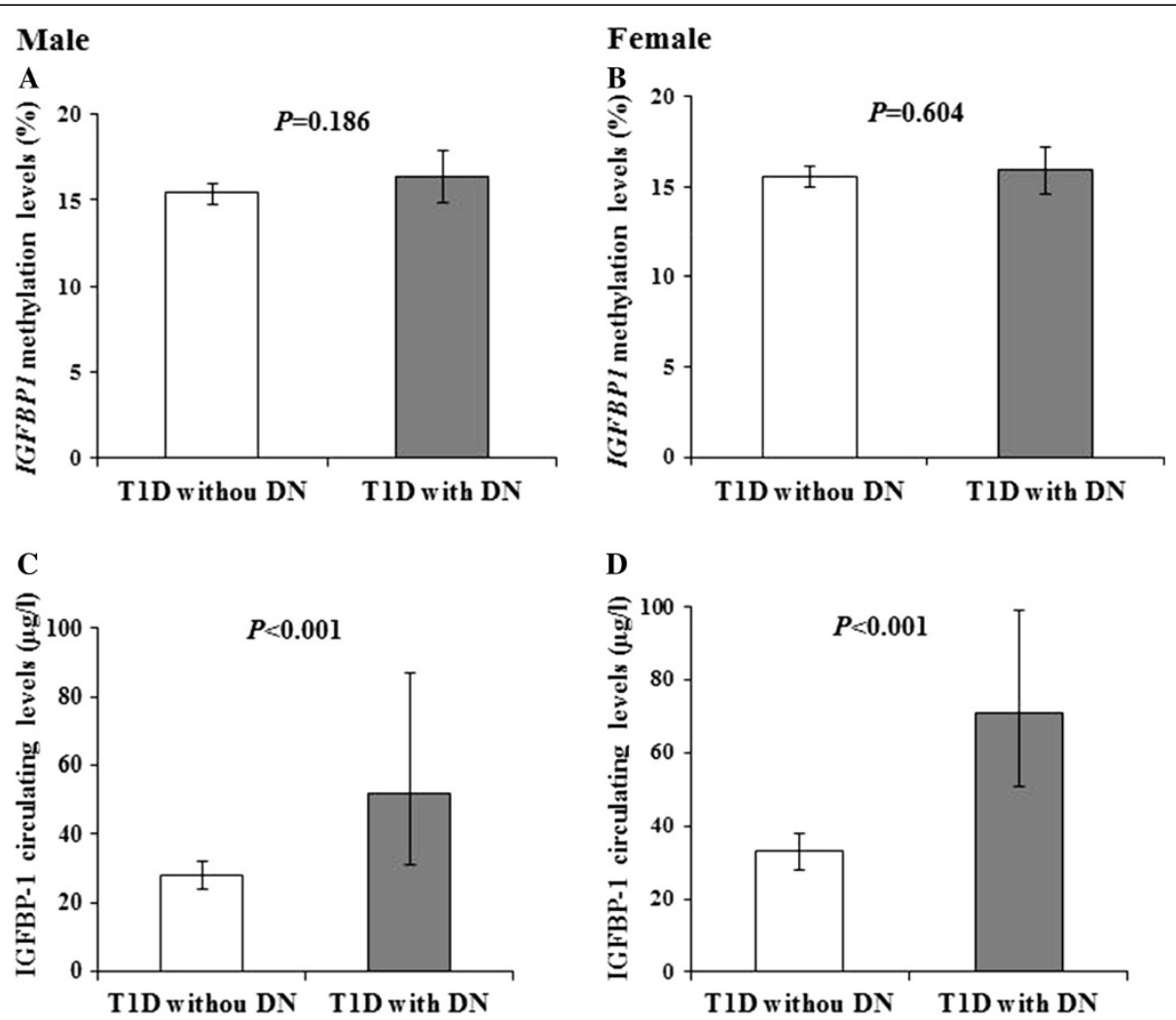

Figure 3 IGFBP1 DNA methylation changes and serum protein variation in Swedish type 1 diabetes patients with and without diabetic nephropathy. A and $\mathbf{B}$ demonstrated the similar IGFBP1 DNA methylation levels between T1D with and without DN in either male (16.4\% versus 15.4\%; $P=0.186$ adjusted for age) or female patients (15.9\% versus $15.6 \%, P=0.604$, adjusted for age). $\mathbf{C}$ and $\mathbf{D}$ indicate that the IGFBP-1 serum levels in T1D patients with DN were significantly increased in both male $(52 \mu \mathrm{g} / \mathrm{L}$ versus $28 \mu \mathrm{g} / \mathrm{L} ; P=0.021)$ and female patients $(71 \mu \mathrm{g} / \mathrm{L}$ versus $33 \mu \mathrm{g} / \mathrm{L} ; P=0.003)$, in comparison with T1D patients without DN. 
female patients in T1D with DN $(52 \mu \mathrm{g} / \mathrm{L}$ versus $71 \mu \mathrm{g} / \mathrm{L}$; $P=0.17)$ or the patients without DN $(28 \mu \mathrm{g} / \mathrm{L}$ versus $33 \mu \mathrm{g} / \mathrm{L} ; P=0.28)$.

\section{IGFBP1 DNA methylation changes and serum protein variation according to $\mathrm{BMI}$}

We recently demonstrated that IGFBP1 DNA methylation changes are not dependent on BMI in T2D [19]. To evaluate whether IGFBP1 DNA methylation changes and serum protein levels were dependent on BMI in T1D, we divided all T1D patients into four groups according to BMI (that is, low-weight group $\left(\mathrm{BMI}<18.5 \mathrm{~kg} / \mathrm{m}^{2}\right.$ ), normal-weight group (18.5 to $25.0 \mathrm{~kg} / \mathrm{m}^{2}$ ), overweight group ( 25.0 to $30.0 \mathrm{~kg} / \mathrm{m}^{2}$ ), and obese group ( $\geq 30.0 \mathrm{~kg}$ / $\mathrm{m}^{2}$ ). We found that circulating IGFBP-1 levels were decreased gradually according to $\mathrm{BMI}(51,39,30$, and $28 \mu \mathrm{g} / \mathrm{L} ; P=0.012)$. However, the IGFBP1 DNA methylation levels were similar among the four groups $(16.0 \%$, $15.9 \%, 15.6 \%$, and $16.0 \% ; P=0.867)$.

\section{Discussion}

We conducted an epigenetic study of the IGFBP1 gene in a Swedish cohort and demonstrated that IGFBP1 DNA methylation levels are decreased in T1D patients compared with NGT subjects. The findings in the present study together with our recent report [19] are summarized in Table 1 and showed that increased and decreased IGFBP1 DNA methylation levels are associated with $\mathrm{T} 2 \mathrm{D}$ and $\mathrm{T} 1 \mathrm{D}$, respectively, implying that IGFBP1 may confer different epigenetic effects in T1D and T2D. Both T1D and T2D are characterized by hyperglycemia, but the underlying pathogenic mechanisms are different. T1D develops on the basis of autoimmune destruction of pancreatic beta cells, which results in insulin deficiency, whereas the hyperglycemia in T2D results from a combination of impaired insulin secretion and insulin resistance.

Although our studies have provided the evidence that IGFBP1 has different DNA methylation levels in T1D and $\mathrm{T} 2 \mathrm{D}$, the molecular mechanism is still unknown. In this study, serum levels of IGFBP-1 in T1D are increased compared with those in NGT subjects, which is consistent with a previous report [15]. The hepatic production of IGFBP-1 protein is regulated mainly by insulin [20]. Therefore, the reduction of IGFBP-1 in T1D is thought to be caused by the insulin deficiency in the patients, although in T2D patients with short duration, the decreased IGFBP-1 concentrations are mainly due to hyperinsulinemia. Thus, we hypothesized that the difference of IGFBP1 DNA methylation levels between T1D and T2D may be related to insulin activity.

DNA methylation levels are known to be affected by age and gender in healthy and disease conditions. The significant interindividual differences in peripheral blood DNA methylation have been discovered in longitudinal studies, with both increase and decrease of the global genome methylation/specific gene methylation in aging $[21,22]$. In our recent report, age-matched NGT subjects and T2D patients were included, and the range of their ages was limited [19]. In the present study, we found a positive relation between IGFBP1 DNA methylation levels and ages in T1D patients. Although similar correlation between IGFBP1 DNA methylation levels and T1D duration was observed, the onset of T1D occurred mainly in childhood, so we believe this correlation was affected mainly by age. The mechanism behind the IGFBP1 DNA methylation with aging is still unknown. Aging-related insulin resistance in T1D could be one of the explanations. In addition, Benbassat et al. [23] showed that serum IGFBP-1 levels were slightly increased throughout adulthood. However, we could not find any correlation between serum IGFBP-1 levels and ages in T1D patients.

In the present study, we showed that both male and female patients with DN had increased IGFBP-1 serum levels compared with those without DN. Flyvbjerg et al. [24] previously conducted experiments with diabetic rats and demonstrated that kidney accumulation of IGF-1 is associated with kidney hypertrophy, which is an early feature of DN. The increased circulating IGFBP-1 allows trapping IGF-1 accumulated in kidneys and may consequently contribute to the development of $\mathrm{DN}$.

Consistent with our recent report of IGFBP1 DNA methylation changes in T2D [19], data from the present study imply that IGFBP1 DNA methylation levels are not dependent on BMI. Furthermore, no correlation between IGFBP1 DNA methylation changes and serum IGFBP-1 levels were observed. Several reasons may be included in the explanation. First, multiple regulators exist for IGFBP-1 circulating levels, including stimulators such as glucagon,

Table 1 A summary of the IGFBP1 DNA methylation and IGFBP-1 serum levels in Swedish men with normal glucose tolerance, type 1 and type 2 diabetes

\begin{tabular}{ccccccc}
\hline Group & Number & IGFBP1 DNA methylation levels (\%) & $\boldsymbol{P}$ value & IGFBP-1 serum levels $(\boldsymbol{\mu g} / \mathbf{L})$ & $\boldsymbol{P}$ value & Reference \\
\hline T2D & 164 & $20.0(19.5-20.5)$ & $P<0.001$ & $18(16-20)$ & 0.014 & Gu T et al. 2013 [19] \\
NGT & 242 & $16.9(16.4-17.1)$ & - & $24(21-26)$ & - & \\
T1D & 304 & $15.6(15.1-16.1)$ & $P<0.001$ & $31(28-35)$ & 0.007 & Present study \\
\hline
\end{tabular}

Data are presented as means $(95 \% \mathrm{Cl})$. NGT, normal glucose tolerance; T1D, type 1 diabetes; T2D, type 2 diabetes; $P$ values were from comparison tests of NGT versus T1D or T2D and adjusted for age. 
cytokines, and cortisol, or suppressors like insulin and amino acids [10,20,25,26]. Second, DNA samples used for methylation analyses were extracted from peripheral blood cells. A limitation in the present study is that we are unable to perform liver tissue-specific methylation analysis in T1D patients and NGT subjects. Third, DNA methylation changes may affect mRNA transcription directly, but not the protein-synthesis process. Although a recent study indicated that DNA methylation analysis with wholeblood samples can be used to reflect the changes in relevant tissues [9], it may be interesting to investigate DNA methylation and mRNA expression levels of the IGFBP1 gene in liver, in order to better understand the correlation between DNA methylation changes and serum protein levels.

\section{Conclusion}

In conclusion, this study demonstrates for the first time that the decreased IGFBP1 DNA methylation levels are associated with T1D but not with DN and contributes further information that increased circulating IGFBP-1 levels are associated with T1D and related DN.

\section{Methods}

\section{Subjects}

This is a case-control study. In total, 778 Swedish subjects were enrolled, consisting of 536 T1D patients (304 male/ 232 female) as diabetic cases and 242 men with normal glucose tolerance (NGT). According to the World Health Organization criteria [27], all patients with T1D were diagnosed before 31 years of age. The duration of T1D was more than 10 years. The NGT subjects were selected from Stockholm Diabetes Prevention Programs (SDPP), as described previously [19].

Clinical characteristics of all subjects with NGT or T1D were summarized in the Additional file 1: Table S1. Urinary AER, 20 to $200 \mu \mathrm{g} / \mathrm{min}$ in at least two consecutive overnight samples was considered microalbuminuria, whereas AER > $200 \mu \mathrm{g} / \mathrm{min}$ in at least two consecutive overnight samples was considered macroalbuminuria. The 51 (25 male/26 female) T1D subjects with macroalbuminuria were classified as the cases of T1D with $\mathrm{DN}$, including two T1D patients who received renal-replacement therapy, whereas 296 (160 male/136 female) T1D patients with persistent normal albuminuria were grouped as the controls of T1D without DN. In addition, 189 (119 male/ 70 female) T1D patients with normal albuminuria or historic microalbuminuria had medical treatments with angiotensin-converting-enzyme inhibitor (ACEI)/angiotensin II-receptor blockers (ARBs). We excluded these 189 patients when we performed comparison analyses between T1D patients with DN and those without DN. Clinical characteristics of all T1D patients with or without DN are represented in Additional file 2: Table S2.
Informed consent was obtained from all subjects, and the study was approved by the ethics committee of the Karolinska Institutet, Stockholm, Sweden.

\section{Serum IGFBP-1 and IGF-1 measurements}

Serum samples were collected from all T1D subjects between $10 \mathrm{AM}$ and $3 \mathrm{PM}$, and fasting serum samples were collected from NGT subjects. All serum samples were saved at $-80^{\circ} \mathrm{C}$ until measurements. We used an in-house RIA, as described previously, to measure serum IGFBP-1 levels [12]. The sensitivity was $3 \mu \mathrm{g} / \mathrm{L}$, and the intra- and interassay CVs were $3 \%$ and $10 \%$, respectively. We also measured total serum IGF-1 levels with another in-house RIA after the separation of IGFs from IGFBPs by acid ethanol extraction and cryoprecipitation [28]. To minimize the interference of remaining IGFBPs, des [1-3] IGF-1 was used as a tracer. The intra- and interassay CVs were $4 \%$ and $11 \%$, respectively.

\section{DNA methylation analysis of IGFBP1}

Genomic DNA was extracted from peripheral blood samples in all subjects. We used the same bisulfite pyrosequencing protocol as recently described in our epigenetic study of the IGFBP1 gene in T2D [19]. This protocol has been widely used for sensitive and quantitative universal pyrosequencing methylation analysis of CpG sites [29]. DNA methylation levels at six CpG sites at 5'-UTR of the IGFBP1 gene were determined by using PyroMark CpG assay (ENSG00000146678), a PyroMark PCR kit (Qiagen, Hilden, Germany) and PyroMark Q96 ID pyrosequencing system (Biotage, Uppsala, Sweden). To control the conversion efficiency of the bisulfite treatment and accuracy in methylation analyses, unmethylated bisulfite converted and unconverted DNA samples (Qiagen) were used.

\section{Statistical analyses}

All data were analyzed by using PASW statistics program (SPSS 20.0; Chicago, IL, USA). Data presented in the tables and figures are either mean with 95\% confidence interval (CI) or geometric mean with $95 \% \mathrm{CI}$ if the data were not normally distributed. Continuous variables between groups were compared by using an unpaired $t$ test or one-way ANOVA followed with Tukey post hoc test. Covariate-adjusted generalized linear models were used when adjusting for age. Linear regression analyses were used to examine the relation between variables. $P$ values $<0.05$ were considered statistically significant.

\section{Additional files}

Additional file 1: Table S1. Clinical characteristics of Swedish subjects with normal glucose tolerance and type 1 diabetes.

Additional file 2: Table S2. Clinical characteristics of Swedish type 1 diabetes patients with and without diabetic nephropathy. 


\section{Competing interest}

The authors declare that no competing interest is associated with this article.

\section{Authors' contributions}

$\mathrm{TG}, \mathrm{HFG}$, and $\mathrm{KB}$ designed the study. HF and KB collected the subjects and clinical data. TG performed experiments and analyzed the data. TG, HFG, and $\mathrm{KB}$ wrote the first draft of the manuscript. All authors contributed to the interpretation of the data and critical revision of the manuscript. All authors read and approved the final manuscript.

\section{Acknowledgements}

The authors thank all Swedish subjects included in this study for their participation, and Elvi Sandberg for laboratory assistance. This work was supported by the Family Erling-Persson Foundation, Swedish Diabetes Association, and Funds from Karolinska Institutet and Stockholm County Council.

\section{Author details}

'Rolf Luft Research Center for Diabetes and Endocrinology, Department of Molecular Medicine and Surgery, Karolinska Institutet, Stockholm, Sweden. ${ }^{2}$ Department of Endocrinology, Metabolism and Diabetes, Karolinska University Hospital, Stockholm, Sweden.

Received: 21 March 2014 Accepted: 13 May 2014

Published: 30 May 2014

\section{References}

1. Pugliese A: The multiple origins of type 1 diabetes. Diabet Med 2013, 30:135-146.

2. Marshall SM: Diabetic nephropathy in type 1 diabetes: has the outlook improved since the 1980s? Diabetologia 2012, 55:2301-2306.

3. Stankov K, Benc D, Draskovic D: Genetic and epigenetic factors in etiology of diabetes mellitus type 1. Pediatrics 2013, 132:1112-1122.

4. Villeneuve LM, Natarajan R: The role of epigenetics in the pathology of diabetic complications. Am J Physiol Renal Physiol 2010, 299:F14-F25.

5. Drong AW, Lindgren CM, McCarthy Ml: The genetic and epigenetic basis of type 2 diabetes and obesity. Clin Pharmacol Ther 2012, 92:707-715.

6. Zhao J, Goldberg J, Bremner JD, Vaccarino V: Global DNA methylation is associated with insulin resistance: a monozygotic twin study. Diabetes 2012, 61:542-546.

7. Ling C, Del Guerra S, Lupi R, Rönn T, Granhall C, Luthman H, Masiello P, Marchetti P, Groop L, Del Prato S: Epigenetic regulation of PPARGC1A in human type 2 diabetic islets and effect on insulin secretion. Diabetologia 2008, 51:615-622.

8. Xu X, Su S, Barnes VA, De Miguel C, Pollock J, Ownby D, Shi H, Zhu H, Snieder $H$, Wang $X$ : A genome-wide methylation study on obesity: differential variability and differential methylation. Epigenetics 2013 8:522-533.

9. Dick KJ, Nelson CP, Tsaprouni L, Sandling JK, Aïssi D, Wahl S, Meduri E, Morange PE, Gagnon F, Grallert H, Waldenberger M, Peters A, Erdmann J, Hengstenberg C, Cambien F, Goodall AH, Ouwehand WH, Schunkert $H_{\text {, }}$ Thompson JR, Spector TD, Gieger C, Trégouët DA, Deloukas P, Samani NJ: DNA methylation and body-mass index: a genome-wide analysis. Lancet 2014, doi:10.1016/S0140-6736(13)62674-4. [Epub ahead of print].

10. Brismar K, Hall K: Clinical applications of IGFBP-1 and its regulation. Growth Regul 1993, 3:98-100.

11. Lee PD, Giudice LC, Conover CA, Powell DR: Insulin-like growth factor binding protein-1: recent findings and new directions. Proc Soc Exp Biol Med 1997, 216:319-357.

12. Petersson U, Ostgren CJ, Brudin L, Brismar K, Nilsson PM: Low levels of insulin-like growth-factor-binding protein-1 (IGFBP-1) are prospectively associated with the incidence of type 2 diabetes and impaired glucose tolerance (IGT): the Söderåkra Cardiovascular Risk Factor Study. Diabetes Metab 2009, 35:198-205.

13. Lewitt MS, Hilding A, Ostenson CG, Efendic S, Brismar K, Hall K: Insulin-like growth factor-binding protein-1 in the prediction and development of type 2 diabetes in middle-aged Swedish men. Diabetologia 2008, 51:1135-1145

14. Gokulakrishnan K, Velmurugan K, Ganesan S, Mohan V: Circulating levels of insulin-like growth factor binding protein-1 in relation to insulin resistance, type 2 diabetes mellitus, and metabolic syndrome (Chennai Urban Rural Epidemiology Study 118). Metabolism 2012, 61:43-46.
15. Hilding A, Brismar K, Degerblad M, Thorén M, Hall K: Altered relation between circulating levels of insulin-like growth factor-binding protein-1 and insulin in growth hormone-deficient patients and insulin-dependent diabetic patients compared to that in healthy subjects. J Clin Endocrinol Metab 1995, 80:2646-2652.

16. Katz LE, Jawad AF, Ganesh J, Abraham M, Murphy K, Lipman TH: Fasting c-peptide and insulin-like growth factor-binding protein-1 levels help to distinguish childhood type 1 and type 2 diabetes at diagnosis. Pediatr Diabetes 2007, 8:53-59.

17. Barkai L, Tombacz A: Alterations in insulin-like growth factor binding protein-1 and sex hormone binding globulin levels in type 1 diabetic adolescents with microalbuminuria. Diabetes Care 2001, 24:605-606.

18. Hong $Y$, Brismar $K$, Hall K, Pedersen NL, de Faire U: Associations between insulin-like growth factor-I (IGF-I), IGF-binding protein-1, insulin and other metabolic measures after controlling for genetic influences: results from middle-aged and elderly monozygotic twins. J Endocrinol 1997 153:251-257.

19. Gu T, Gu HF, Hilding A, Sjöholm LK, Ostenson CG, Ekström TJ, Brismar K: Increased DNA methylation levels of the insulin-like growth factor binding protein 1 gene are associated with type 2 diabetes in Swedish men. Clin Epigenet 2013, 5:21. Doi: 10.1186/1868-7083-5-21.

20. Brismar K, Fernqvist-Forbes E, Wahren J, Hall K: Effect of insulin on the hepatic production of insulin-like growth factor-binding protein(IGFBP-1), IGFBP-3, and IGF-I in insulin-dependent diabetes. J Clin Endocrinol Metab 1994, 79:872-878

21. Kaminsky Z, Wang SC, Petronis A: Complex disease, gender and epigenetics. Ann Med 2006, 38:530-544.

22. Bjornsson HT, Sigurdsson MI, Fallin MD, Irizarry RA, Aspelund T, Cui H, Yu W, Rongione MA, Ekström TJ, Harris TB, Launer LJ, Eiriksdottir G, Leppert MF Sapienza C, Gudnason V, Feinberg AP: Intra-individual change over time in DNA methylation with familial clustering. JAMA 2008, 299:2877-2883.

23. Benbassat CA, Maki KC, Unterman TG: Circulating levels of insulin-like growth factor (IGF) binding protein-1 and -3 in aging men: relationships to insulin, glucose, IGF, and dehydroepiandrosterone sulfate levels and anthropometric measures. J Clin Endocrinol Metab 1997, 82:1484-1491.

24. Flyvbjerg A, Bornfeldt KE, Marshall SM, Arnqvist HJ, Orskov H: Kidney IGF-I mRNA in initial renal hypertrophy in experimental diabetes in rats. Diabetologia 1990, 33:334-338.

25. Hilding A, Möller C, Hall KE: Glucagon and GLP-1 stimulate IGFBP-1 secretion in Hep G2 cells without effect on IGFBP-1 mRNA. Growth Horm IGF Res 2002, 12:60-68.

26. Samstein B, Hoimes ML, Fan J, Frost RA, Gelato MC, Lang CH: IL-6 stimulation of insulin-like growth factor binding protein (IGFBP)-1 production. Biochem Biophys Res Commun 1996, 228:611-615.

27. Alberti KG, Zimmet PZ: Definition, diagnosis and classification of diabetes mellitus and its complications; Part 1: diagnosis and classification of diabetes mellitus provisional report of a WHO consultation. Diabet Med 1998, 15:539-553.

28. Bang P, Eriksson U, Sara V, Wivall IL, Hall K: Comparison of acid ethanol extraction and acid gel filtration prior to IGF-I and IGF-II radioimmunoassays: improvement of determinations in acid ethanol extracts by the use of truncated IGF-I as radioligand. Acta Endocrinol (Copenh) 1991, 124:620-629.

29. Colella S, Shen L, Baggerly KA, Issa JP, Krahe R: Sensitive and quantitative universal pyrosequencing methylation analysis of $\mathrm{CpG}$ sites. Biotechniques 2003, 35:146-150

doi:10.1186/1868-7083-6-10

Cite this article as: Gu et al.: Epigenetic analyses of the insulin-like growth factor binding protein 1 gene in type 1 diabetes and diabetic nephropathy. Clinical Epigenetics 2014 6:10. 